It seems to me, therefore, that many pronouncements regarding this unique South African fossil will have to be revised, and in fact that we cannot do tion of it as published in Nature of February 7, 1925.

Department of Anatomy,

M. R. Drennan.

University,

Cape Town.

June 22.

1 Nature, 141, 1010 (June 4, 1938).

"Drennan, M. R., "The Florisbad Skull and Brain Cast", Trans. Roy. Soc. S.A., 25, Pt. 1 (1937).

"Dreyer, T. F., "The Archæology of the Florisbad Deposits", Arch.

Navorsing van die Nasionale Museum, 1 , Agste stuk. Bloemfontein (1938).

“ NATURE, 141, 828 (May 7, 1938).

\section{Kymograph Studies of Physiological (Respiratory) Concomitants in Two Types of Attentional Adaptation}

THE group or phylobiological researches which I have carried out in the field of behaviour-disorders indicate that the neuroses and psychoses are aggravabetter than go back to Dart's first classical descrip

and neurotic attitudes are eliminated, and there occurs a re-centring of interest which gives precedence to internally motivated, phyletically co-ordinated trends. Physiological (neuromuscular) modifications related to the organism's phantasy sphere have thus been differentiated from physiological modifications concomitant to the organism's direct relation to environmental reality.

Recent instrumental experimentation shows that the pattern of cotention is characterized by a scarcity of eye- and lid-movements and by specific changes of respiration, namely, $(a)$ a markedly decreased frequency, $(b)$ an increased amplitude of the respiratory movements, and $(c)$ in certain subjects a decreased inspiration-expiration ratio. The respiratory curve, as obtained by thoracic and abdominal pneumographs, was recorded by the wax paper kymograph devised by Volkmann and Gerbrands (Harvard). The diminution in frequency was from a normal average of $12 \cdot 8$ to an average of $4 \cdot 2$ respirations per minute during cotention.

It was possible to differentiate these respiratory alterations sharply from other slight modifications occurring under varying conditions of mental rest or activity. The respiratory changes may be considered as part manifestations of the two types of attentional adaptation. They set in immediately with the altered attention ; they occur automatically ; and they are not affected by opening or closing the eyes.

The differentiation of the two forms of attention is of special interest in relation to the problem of behaviour-disorders. Under conditions of cotention, symbolic projections possessing the emotionally coloured content characteristic of neurotic reactions are automatically arrested. The cotentive reaction may be brought about by training. Experimentation with respiratory changes is being continued in the laboratory of the Lifwynn Foundation, and other physiological patterns which underlie the two types of attentional adaptation are being investigated.

Trigant Burrow. (Scientific Director.)

tions of discrepant processes existing within society generally. In connexion with investigations of adaptive reactions, I have differentiated two internal attentional patterns ${ }^{1}$ : (1) The pattern concomitant to ordinary attention in which the individual focuses upon external objects or upon images or symbols relating to them; (2) a pattern which I have distinguished as cotention, in which the individual focuses upon tensions located predominantly in the region of the eyes or in the segment of the symbolic activity.

The second pattern precludes the usual play of phantasies and the customary affects and strivings commonly adhering to mental imagery. Instead there is sensed the organism's generalized tensions as contrasted with the more specifically localized tensions of the symbolic segment. The competitiveness and self-concern characteristic alike of so-called normal
The Lifwynn Foundation, New York. April 18.

${ }^{1}$ Reported in my book, "The Biology of Human Conflict-An Anatomy of Behavior, Individual and Social" (New York The Macmillan Company, 1937) (see NatuRE, March 12, 1938,
p. 462).

\section{Chromosome Structure}

IT was recently shown ${ }^{1}$ that the somatic chromosomes of Trillium are composed of four strands intertwined in pairs at metaphase, while in anaphase and telophase they contain two spirally twined threads.

Recent cytological investigations of Crocus sativus (saffron) yield further crucial evidence regarding chromosome structure. This cultivated form is 